\title{
TORSION OF HEMATOSALPINX WITH HEMOPERITONEUM
}

Lakshmikantha. G, Dwarakanath. L, Reena Kumari

1. Assistant Professor, Department of Obstetrics \& Gynaecology, Sri Siddhartha Medical College, Tumkur, Karnataka, India.

2. Associate Professor, Department of Obstetrics \& Gynaecology, Sri Siddhartha Medical College, Tumkur, Karnataka, India.

3. Resident, Department of Obstetrics \& Gynaecology, Sri Siddhartha Medical College, Tumkur, Karnataka, India.

\section{CORRESPONDING AUTHOR}

Dr. Lakshmikantha.

$\mathrm{G}, \# 249,3^{\text {rd }}$ A main,

Near Amba Bhavani Circle,

NE of NR Mohalla, Mysore,

Karnataka, India 570007

E-mail: drlakshmikanthag@yahoo.co.in

Ph: 00919740810611

CAPSULE: Hematosalpinx with hemoperitoneum is a rare combination seen only after rupture or impending rupture of hematosalpinx.

KEYWORDS: hematosalpinx, torsion, hemoperitoneum

ABSTRACT: In cases presenting with hemoperitoneum diagnosis of ruptured ectopic pregnancy should be made unless proved otherwise during reproductive age. Rarely ruptured ovarian cyst may be a cause. Hematosalpinx can undergo torsion due to circulatory imbalance and the same can present as hemoperitoneum due to rupture. We present a rare case of torsion of hematosalpinx without an obvious rupture presenting as hemoperitoneum.

INTRODUCTION: Acute abdomen is one of the important presentations in gynaecological practice, the common causes being acute pelvic inflammatory disease, torsion of ovarian cyst and ectopic pregnancy apart from surgical causes. Tubal pregnancy is an important diagnosis to be ruled out in any female patient presenting with acute abdomen, especially post sterilisation. We present a rare case of hematosalpinx with torsion at its pedicle with hemoperitoneum who presented with acute abdomen.

CASE REPORT: A 40years old Para4, sterilised 20years back was admitted on 7/9/11 with complaints of acute pain in the abdomen for one day. Her menstrual cycles were regular and LMP was 8days ago. There was no dysmenorrhea and no history suggestive of obvious nongynaecological cause of acute abdomen.

On examination she was very pale but her vitals were stable with pulse rate $90 / \mathrm{min}$ and blood pressure 110/70 mmHg. There was tenderness in left iliac fossa with guarding but no rigidity. Bowel sound was present. Bimanual examination revealed normal sized uterus with tender cystic mass in left adnexa approximately $10 \mathrm{x} 4 \mathrm{~cm}$. There was cervical motion tenderness. UPT was negative. Hemoglobin was 6 gm\%. Sonography showed a well defined cystic lesion measuring 10x4cm.in the left adnexa. B/L ovaries were normal and separate from mass and free fluid was present in POD. Diagnosis of torsion paraovarian cyst was made and patient was posted for emergency laparotomy. On laparotomy there was left sided hematosalpinx 
(10x8x5) cm with three twists at its pedicle and about $200 \mathrm{ml}$ hemoperitoneum. The left ovary was normal and rest of the pelvic structures did not reveal any abnormality. Left salpingectomy was done. Post-operative period was uneventful. Histopathology report revealed grossly cystically dilated tube measuring $10 \times 8.5 \times 5.5 \mathrm{cms}$; cut section shows collection blood clot inside the distended tube with areas of hemorrhage on tubal wall. Microscopy showed fallopian tube with ulceration of mucosa, large areas of hemorrhage, congested blood vessels and ischaemic necrosis suggestive of hematosalpinx with torsion. No malignant suspicious area was seen.

DISCUSSION: Hematosalpinx is usually reported in case of ectopic pregnancy ${ }^{1}$. Serous borderline tumour of the fallopian tube presented as hematosalpinx ${ }^{2}$ or ruptured hematosalpinx ${ }^{3}$.Hematosalpinx has been rarely observed after medical abortion with oral mifepristone or misoprostol ${ }^{4}$. Acute abdominal pain seen usually due to torsion of adnexa or cysts at its pedicle. Hematosalpinx may be associated with endometriosis and tubal carcinoma.

In our case the exact cause of hematosalpinx cannot be made. However the tube twisted by itself most probably is causing the existing hydrosalpinx into a hematosalpinx due to rupture of veins in to hydrosalpinx. Blood escaping(oozing) from the thinned out walls would have lead to hemoperitoneum.Salpingectomy either by laparoscopy or laparotomy is the treatment of choice in these cases.

CONCLUSION: Intraabdominal bleed should be strongly considered in cases of acute pain abdomen with severe pallor even with otherwise stable vitals and if radiology reveals a mass or free fluid laparoscopy or laparotomy is justified.

CONFLICT OF INTEREST: None to disclose

\section{REFERENCES:}

1. Sindos $\mathrm{M}$, Wang $\mathrm{TF}$, Pisal $\mathrm{N}$ et al. Bilateral hematosalpinx in case of ectopic pregnancy: a clinical dilemma. Am J ObstetGynecol 2003: 189:892-3

2. Kraservic M, Stankovic T, Petrovic 0 et al. Serous borderline tumour of the fallopian tube presented as hematosalpinx: a case report. BMC Cancer 2005; 5:129

3. Bakos 0 , Berglund L. Imperforate hymen and ruptured hematosalpinx: a case report with a review of the literature. J Adolesc Health 1999;24:226-8

4. Lin SK, Ho ES, Chen YJ.Hematosalpinx: an unusual complication after medical abortion with oral mifepristone and misoprostol. Ultrasound ObstetGynecol 2005;25:416-7 


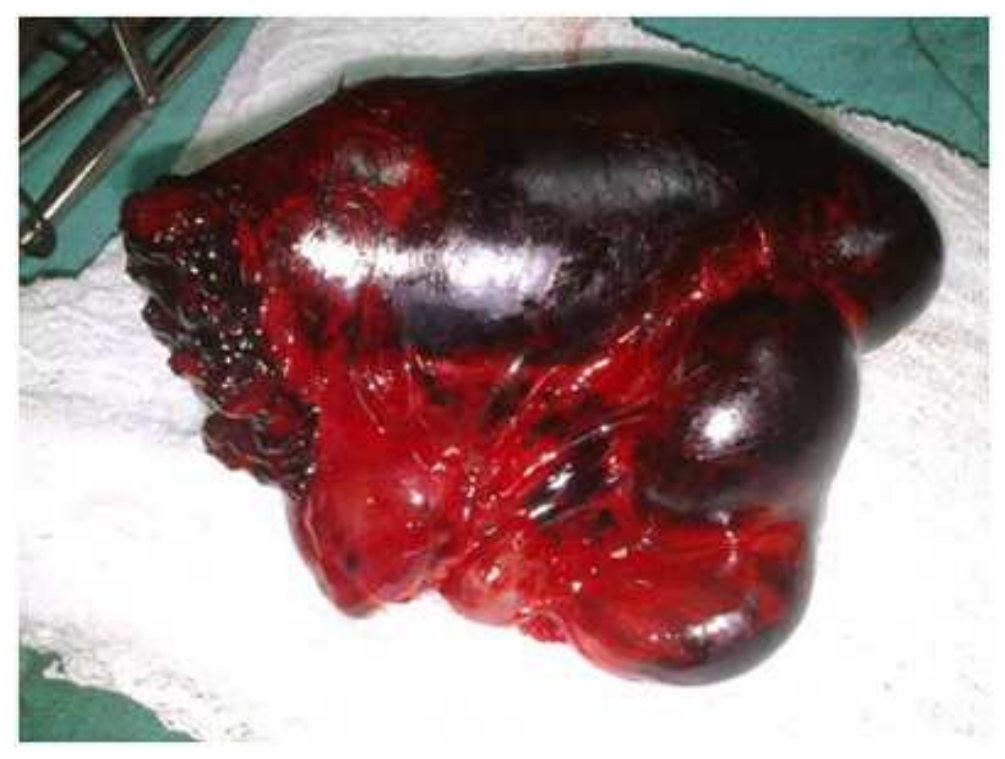

FIGURE 1: HEMATOSALPINX WITH AREAS OF HEMORRHAGE FROM TUBAL WALL (10x8.5x5.5 cms). 